Tersedia online di http://ejurnal.stisipolcandradimuka.ac.id/index.php/JurnalPublisitas/

\title{
Analisis Strategi Pengembangan Destinasi Wisata Museum Negeri Sumatera Selatan Balaputra Dewa Oleh Dinas Pariwisata Di Kota Palembang
}

\author{
Margareta $^{1}$, Novia Kencana ${ }^{2}$, Doris Febriyanti ${ }^{3}$, \\ ${ }^{1}$ Program Studi Administrasi Publik, STISIPOL Candradimuka Palembang \\ ${ }^{2}$ Program Studi Ilmu Pemerintahan, Universitas Indo Global Mandiri Palembang \\ ${ }^{3}$ Program Studi Ilmu Pemerintahan, Universitas Indo Global Mandiri Palembang \\ Email: margareta@stisipolcandradimuka.ac.id ${ }^{1}, \underline{\text { kencananovia@ uigm.ac.id }}{ }^{2}, \underline{\text { dorishakiki@uigm.ac.id }}^{3}$
}

\begin{abstract}
ABSTRAK
Museum Balaputra Dewa merupakan salah satu Museum negeri yang ada di provinsi Sumatra selatan yang di kelompokan ke dalam 5 (lima) pameran besar dan menyimpan berbagai macam koleksi. Adapun yang menjadi Identifikasi masalah kurangnya sarana dalam mempromosikan Museum, kurangnya pemeliharaan dan pengawasan Museum, kurangnya minat masyarakat mengenal sejarah masa lampau, kurangnya penyediaan Cinderamata diMuseum. Penelitian ini bertujuan mengetahui bagaimana strategi Museum Balaputra Dewa dapat dikembangkan agar lebih maksimal dan hambatan-hambatan apa saja yang dihadapi. Data yang dikumpulkan dengan metode observasi, wawancara dan dokumentasi. Teknis analis data dalam penelitian ini yaitu analisis deskriptif kualitatif. Tahapan perumusan strategi diawali dengan analisis internal dan eksternal tahapan selanjutnya adalah tahapan analisis Matriks SWOT. Hasil analisa maka strategi pengembangan Museum negeri Balaputra Dewa masuk ke dalam langkah ketiga Matriks SWOT. Alternatif strategi yang digunakan adalah strategi yang meminimalkan kelemahaan (weaknesses) untuk memanfaatkan peluang (Opportunities) itu harus dimanfaatkan untuk meminimalkan kelemahan yang dimiliki serta digunakan untuk mengurangi ancaman eksternal.Strategi tersebut menjadi jawaban penelitian untuk mengatasi permasalahan yang terdapat di Museum Balaputra Dewa sehingga pengembangan di Museum dapat diterapkan dengan optimal.
\end{abstract}

Kata kunci: Strategi, SWOT, Museum Edukasi

\begin{abstract}
Balaputra Dewa Museum is one of the state Museums in South Sumatra province, which is grouped into 5 (five) major exhibitions and holds various kinds of collections. As for the identification of the problem of lack of facilities in promoting Museums, lack of maintenance and supervision of Museums, lack of public interest in knowing past history, lack of provision of souvenirs in Museums. This research aims to find out how the Museum's strategy of Balaputra Dewa is developed so that it can be maximized and what obstacles are faced. Data collected by the method of observation, interviews and documentation. The data analysis technique in this research is descriptive qualitative analysis. The strategy formulation stage begins with internal and external analysis. The next stage is the SWOT Matrix analysis stage. The result of the analysis shows that the national Museum development strategy of Balaputra Dewa goes into the
\end{abstract}


third step of the SWOT Matrix. The alternative strategy used is a strategy that minimizes weaknesses to take advantage of opportunities (Opportunities) that must be used to minimize weaknesses and be used to reduce external threats. This strategy is the answer to research to overcome problems in the Balaputra Dewa Museum so that development in Museum can be applied optimally.

Keywords: Strategy, SWOT, Museum of Education

\section{PENDAHULUAN}

Peraturan pemerintah Republik Indonesia Nomor 66 tahun 2015 tentang Museum menjelaskan bahwa Museum adalah lembaga tempat penyimpanan, perawatan,pengaman, dan pemanfaatan benda-benda bukti materil hasil budaya manusia serta alam dan lingkungannya guna menunjang upaya perlindungan dan pelestrian kekayaan budaya bangsa. keberadaan Museum di Indonesia sendiri belum bisa diandalkan menjadi tempat tujuan kunjungan yang bisa menghasilkan devisa sebagaimana Museum negara-negara maju. Bukan hanya pembangunan fisik yang harus ditata ulang, Sumber Daya Manusia pun harus pula ditingkatkan. Selain itu, pembangunan Museum bukan hanya tanggung jawab pemerintah semata-mata, tetapi juga tanggung jawab semua pihak. Selama pengelolaannya tidak profesional dan pembangunan fisiknya tidak nyaman serta informasi tentang data-data yang ada diMuseum tidak disajikan dengan baik, selama itu pula berbagai Museum yang ada di indonesia belum bisa diandalkan untuk menjadi tempat tujuan kunjungan.

Salah satu objek wisata bersejarah di indonesia adalah Museum Negeri Sumatera Selatan Balaputra Dewa yang terletak di jalan Srijaya No.288 KM 5.5, Alang Alang Lebar, Kota Palembang,
Sumatera Selatan. Museum ini termasuk kedalam objek wisata yang memiliki potensi ilmu pengetahuan dan teknologi (IPTEK). Hal ini menjelaskan bahwa Museum bukan hanya menjadi obyek wisata namun juga sebagai tempat belajar. Dengan berkembangnya Museum menjadi lebih baik, maka akan mampu memberikan lapangan kerja bagi masyarakat.

Museum Negeri Sumatera Selatan Balaputera Dewa menyimpan berbagai koleksi yang dibagi menjadi 10 macam kategori yaitu histografi atau historika (cerita-cerita), etnografi, feologi, keramik, alat-alat teknologi modern, seni rupa (berupa ukiran), flora-fauna (biologika) dan geologi serta terdapat rumah limas juga rumah ulu ali. Koleksikoleksi di Museum Balaputra Dewa ditempatkan dalam 5 (lima) Tata pameran besar 1. Masa Prasejarah Sumatera Selatan, 2. Masa Sriwijaya, Kesultanan Palembang dan Masa Kolonial, 3. Kerajinan Tradisional Sumatera Selatan, 4. Bangsa Arca, 5. Galeri Malaka.

Peningkatan kuantitas pengunjung akan lebih baik apabila diikuti oleh peningkatan kualitas pengunjung itu sendiri. Jika Peningkatan kuantitas tidak diikuti peningkatan kualitas, maka yang terjadi Museum Balaputra Dewa tidak berbeda jauh dari hanya sekedar tempat rekreasi seperti lainnya. Beberapun 
banyaknya pengunjung yang datang ke Museum Balaputra Dewa tidak akan berarti jika mereka tidak mengetahui apa makna yang ada pada Museum dan benda koleksinya. Karena kebanyakkan pengunjung yang datang hanya untuk berwisata saja. Untuk itu perlu pendidikan dan pelatihan yang baik bagi para pemandu (guide) di Museum Balaputra Dewa agar dapat menjelaskan sejarah dan isi Museum Balaputra Dewa secara keseluruhan sehingga dapat memberikan pelajaran yang berharga untuk pengunjung yang datang. Museum Balaputra Dewa yang sangat dibanggakan dikota palembang Sumatera Selatan ini seharusnya memiliki strategi perkembangan dan inovasi/proses yang lebih beragam dari pada Museum swasta dan tidak kalah dengan Museum negeri lainnya namun strategi perkembangan serta inovasi/proses yang diterapkan di Museum Balaputra Dewa belum terlihat dan dirasakan oleh para pengunjung maupun Museum Balaputra Dewa itu sendiri.

Hal ini menjadi salah satu masalah yang harus di pecahkan. Untuk mengatasi berbagai permasalahan di Museum Balaputra Dewa, maka dibutuh menganalisis strategi yang lebih tepat dalam mengembangkan Museum Balaputra Dewa agar menjadi lebih baik lagi sehingga menarik pengunjung. Lingkungan internal dan eksternal menjadi langkah penting untuk menganalisis strategi pengembangan yang ada di Museum Balaputra Dewa dengan lingkungan juga kita bisa mengetahui kekurangan yang harus dibenahi dan apa yang menghambat berjalan nya strategi yang ada agar tidak mengganggu eksistensi/kesempurnaan Museum Balaputra Dewa serta ancaman dari kompetitor/pesaing sehingga dapat diatasi lebih awal. Dengan strategi pengembangan yang ada di Museum Balaputra Dewa diharapkan menghasilkan pengembangan yang bermanfaat bagi perbaikan Museum Balaputra Dewa itu sendiri. Perkembangan strategi menjadi sangat penting karena strategi merupakan kerangka yang mendasar.

Identifikasi Masalah dalam penelitian ini, adalah: [1] Masih kurang nya sarana dalam mempromosikan Museum Negeri Sumatera Selatan Balaputera Dewa; [2] Masih kurangnya pemeliharaan dan pengawasan di Museum Negeri Sumatera Selatan Balaputera Dewa; [3] Kurangnya minat masyarakat untuk mengenal sejarah kejayaan masa lampau yang ada di Museum Negeri Sumatera Selatan Balaputera Dewa; [4] Masih kurangnya penyediaan barang-barang cinderamata yang ada di Museum Negeri Sumatera Selatan Balaputera Dewa.

Rumusan Maslaah pada penelitian ini adalah, Strategi apa yang dapat dilaksanakan untuk meningkatkan pengembangan Museum Negeri Sumatera Selatan Balaputera Dewa sebagai daya tarik wisata.

Tujuan Penelitian ini adalah mengetahui factor pendorong dan penghambat di Museum Negeri Sumatera Selatan Balaputera Dewa sebagai daya tarik wisata dan Mengetahui strategi yang dapat dilaksanakan untuk meningkatkan pengembangan Museum Negeri Sumatera 
Selatan Balaputera Dewa sebagai daya tarik wisata.

\section{TINJAUAN PUSTAKA}

Kamus Besar Bahasa Indonesia karangan Suharso dan Ana Retnoningsih (2005), analisis adalah penyelidikan terhadap suatu peristiwa (karangan, perbuatan dan sebagainya) untuk mengetahui keadaan yang sebenarnya (sebab musabab, duduk perkara dan sebagainya). Dalam Kamus Besar Bahasa Indonesia Departemen Pendidikan Nasional (2005) menjelaskan bahwa analisis adalah penyelidikan terhadap suatu peristiwa untuk mengetahui keadaan yang sebenarnya

Menurut Prof. Dr. Sondang P. Siagian, dalam bukunya Manajemen Strategi (2005) definisi manajemen strategi adalah Serangkaian keputusan dan tindakan mendasar yang dibuat oleh manajemen puncak dan diimplementasikan oleh seluruh jajaran organisasi dalam rangka pencapaian tujuan organisasi tersebut.

Definisi yang ada dapat ditarik kesimpulan bahwa yang dimaksud dengan manajemen strategi adalah suatu seni dan ilmu dari pembuatan (formulating), penerapan (implementing) dan evaluasi (evaluating) keputusankeputusan strategi antar fungsi-fungsi yang memungkinkan sebuah organisasi mencapai tujuan-tujuan masa datang (Wahyudi,1996;15).

Manajemen strategi berhubungan dengan upaya memecahkan persoalan strategi dan perencanaan dan bagaimana strategi tersebut dilaksanakan dalam dunia nyata. Paling tidak ada 3 (tiga) elemen penting dalam manajemen strategi yaitu adanya

[1] Analisis strategi dimana penyusun strategi yang bersangkutan berupaya untuk memahami posisi strategi organisasi yang bersangkutan. [2] Pilihan strategi yang berhubungan dengan perumusan aneka macam arah tindakan, evaluasi, dan pilihan antara mereka. 3.Implementasi strategi yang berhubungan dengan merencanakan bagaimana pilihan strategi dapat dilaksanakan.

Tahapan proses Manajemen Strategi:

a. Perumusan Strategi Visi dan Misi

Tahapan Manajemen strategi di awali dengan perumusan strategi.

b. Analisis Lingkungan

Analisis lingkungan merupakan suatu proses dalam manejemn strategi yang bertujuan untuk memantau lingkungan perusahaan.

\section{c. Analisis SWOT}

Setelah melakukan analisis lingkungan eksternal dan internal diharapkan kita sudah dapat memiliki gambaran perusahaan dalam dunia persaingan. Biasanya ada dua indikator utama yang digunakan untuk menentukan arah organisasi. Pertama adalah misi yang berfungsi sebagai alasan yang menjelaskan mengapa organisasi tersebut ada. Selain itu juga misi ini diharapkan memberikan gambaran yang baik dan citra yang diinginkan dari masyarakat sebelum sebua misi dan tujuan ditentukan perusahaan seharusnya memiliki visi secara 
singkat visi menjelaskan tentang bisnis perusahaan lebih kepada penetapan target dan sedapat mungkin terukur dan tercapai target yang diharapkan. Tahapan Prosen Manajemen Strategi dapat dilihat di Gambar 1.

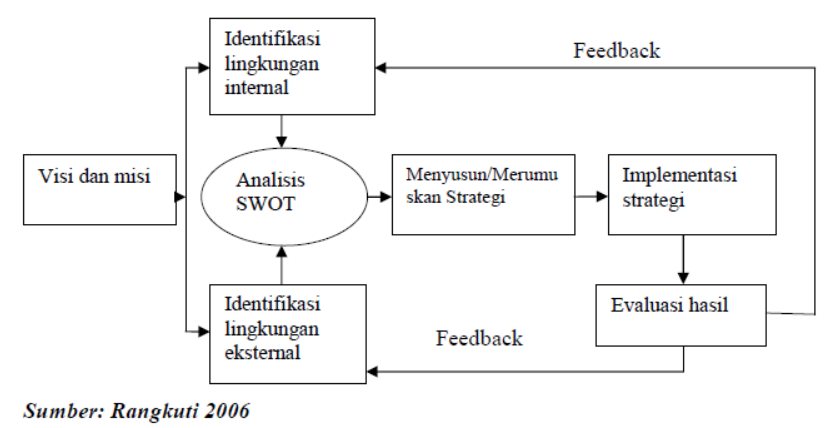

Gambar 1 Proses Manajemen Strategi

Faktor eksternal terdiri dari peluang dan ancaman, sedangkan factor internal terdiri dari kekuatan dan kelemahan. Dalam analisis SWOT, dilakukan perbandingan antara faktor-faktor strategis internal maupun eksternal untuk memproleh strategi terhadap masingmasing faktor tersebut, kemudian dilakukan scoring. Berdasarkan hasil yang diperoleh kemudian ditentukan focus rekomendasi strategi.

Berdasarkan Matriks SWOT, didapatkan 4 langkah strategi yaitu sebagai berikut:

a. Strategi SO

Strategi ini dibuat berdasarkan jalan pikiran perusahaan, yaitu dengan memanfaatkan seluruh kekuatan untuk merebut dan memanfaatkan peluang sebesar-besarnya.Strategi SO menggunakan kekuatan internal perusahaan utuk memanfaatkan peluang eksternal. b. Strategi ST

Strategi ini menggunakan kekuatan yang dimiliki perusahaan untuk mengatasi ancaman. Strategi ST menggunakan kekuatan internal perusahaan untuk menghindari atau mengurangi dampak ancaman eksternal.

c. Strategi WO

Strategi ini diterapkan berdasarkan pemanfaatan peluang yang ada dengan cara meminimalkan kelemahan yang ada. Strategi WO bertujuan untuk memperbaiki kelemahan internal dengan memanfaatkan peluang eksternal.

d. Strategi WT

Strategi ini didasarkan pada kegiatan yang bersifat defensif dan berusaha meminimalkan kelemahan serta menghindari ancaman. Strategi WT bertujuan untuk mengurangi kelemahan internal dengan menghindari ancaman eksternal.

e. Menyusun/Merumuskan Strategi

Formulasi Strategi adalah proses merancang dan menyeleksi berbagai strategi yang pada akhirnya menuntun pada pencapaian misi dan tujuan organisasi. Formulasi strategi menentukan aktivitas-aktivitas yang berhubungan dengan pencapaian tujuan. Aktivitas tersebut dapat dikelompokan kedalam 3 (tiga) kelompok yaitu : analisis strategi, perencanaan strategi, pemilihan strategi. Formulasi strategi membutuhkan data dan informasi yang akurat dari analisis lingkungan. 


\section{Kerangka Pemikiran}

1. Masih kurangnya sarana dalam mempromosikan Museum Negeri Sumatera Selatan Balaputra Dewa.

2. Masih kurangnya pemeliharaan dan pengawasan di Museum Negeri Sumatera Selatan Balaputra Dewa.

3. Kurangnya minat masyarakat untuk mengenal sejarah kebudayaan nenek moyang yang ada di Museum Negeri Sumatera Selatan Balaputra Dewa.

4. Masih kurangnya penyediaan barang-barang cinderamata

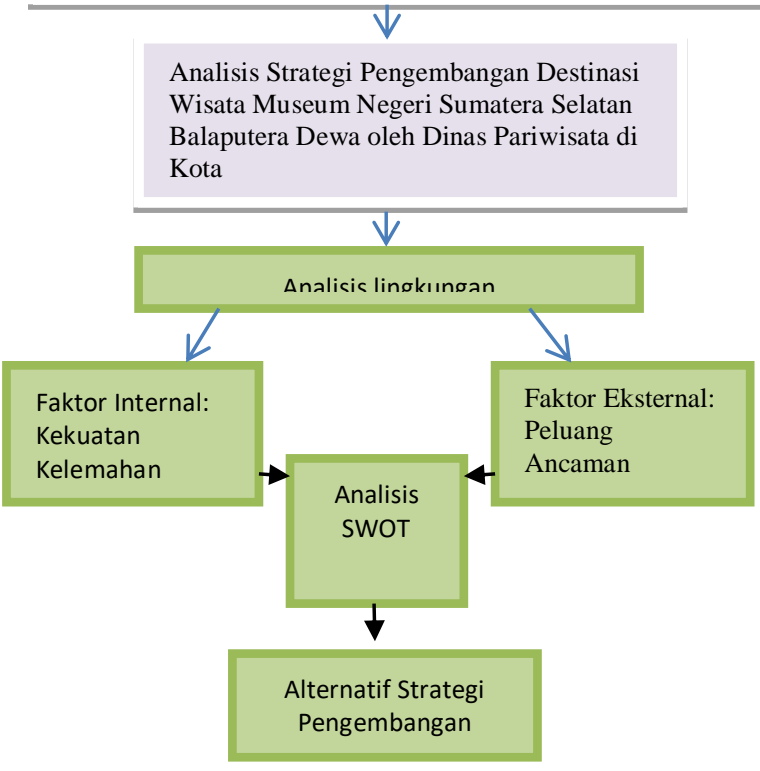

Sumber: diolah oleh Penulis (Rangkuti, 2006)

\section{Gambar 2. Kerangka Pemikiran}

\section{METODE PENELITIAN}

Rancangan penelitian ini bersifat deskriptif kualitatif. Jenis penelitian deskriptif kualitatif yaitu suatu penelitian yang menghasilkan data secara deskriptif kualitatif merupakan salah satu dari jenis penelitian yang termasuk dalam jenis penelitian kualitatif yang berupa fakta, keadaan, fenomena secara lisan maupun tertulis dari setiap prilaku orang yang dicermati penelitian ini sendiri tidak mengadakan perhitungan. Data yang dikumpulkan bukan angka- angka melainkan berupa gambar dan kata-kata.
Semua yang dikumpulkan akan menjadi sebua kunci terhadap apa yang sudah diteliti. Dengan demikian laporan ini akan berisi kutipan-kutipan untuk memberikan laporan yang berupa gambaran penyajian.

\section{Variabel Penelitian}

Penelitian ini yang menjadi indikatornya, secara lebih rinci tertera pada Tabel 1.

\section{Tabel 1. Indikator Penelitian}

\begin{tabular}{|c|c|c|}
\hline Variabel & Dimensi & Indikator \\
\hline $\begin{array}{l}\text { Strategi } \\
\text { Pengemba } \\
\text { ngan } \\
\text { Destinasi } \\
\text { Wisata } \\
\text { Museum } \\
\text { Negeri } \\
\text { Sumatera } \\
\text { Selatan } \\
\text { Balaputera } \\
\text { Dewa }\end{array}$ & Aspek Internal & 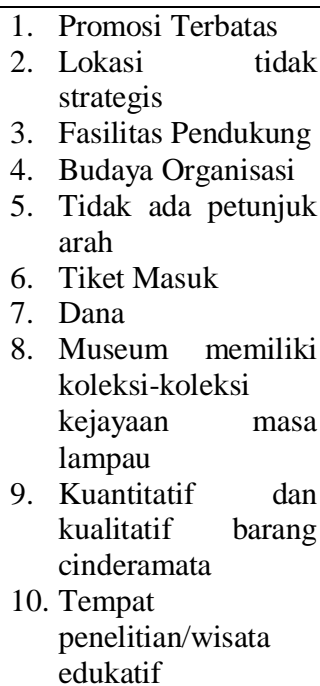 \\
\hline & $\begin{array}{l}\text { Aspek } \\
\text { Eksternal }\end{array}$ & $\begin{array}{ll}\text { 1. } & \text { Kebijakan } \\
\text { Pemerintah } \\
\text { 2. Persaingan tempat } \\
\text { hiburan } \\
\text { 3. Masuknya budaya } \\
\text { asing } \\
\text { 4. Kemajuan IPTEK } \\
\text { 5. Destinasi } \\
\text { Pariwiwsatamenawa } \\
\text { rkan produk } \\
\text { 6. Pencurian } \\
\text { 7. Kenyamanan } \\
\text { 8. Perusakan } \\
\text { 9. Kondisi social } \\
\text { budaya masyarakat } \\
\text { yang menilai wisata } \\
\text { Museum } \\
\text { 10. Koordinasi dinas } \\
\text { terkait }\end{array}$ \\
\hline
\end{tabular}




\section{Teknik Pengumpulan Data}

Penelitian ini dilakukan dengan metode, adalah Observasi, Wawancara, dan Dokumentasi.

\section{Key Informant}

Penelitian ini ditentukan berdasarkan teknik purposive sampling. Infroman yang bermaksud tersebut adalah:

1. Kepala Museum Sumatera Selatan Balaputera Dewa

2. Kepala Sub Bagian Tata Usaha

3. Pelaksana

4. Pengunjung

\section{HASIL PENELITIAN}

Berikut ini adalah kekuatan dan kelemahan yang dimiliki oleh Museum sumatera selatan Balaputra Dewa yang tergolong pada lingkungan internal dan peluang, ancaman yang tergolong pada lingkungan ekternal.

\section{Analisis Lingkungan Internal}

Museum Negeri Sumatera Selatan Balputra Dewa sulit berkembang secara signifikan karena program promosi yang ada belum optimal. serta kurangnya dana dari pemerintah. Dana itu dibagi bagi lagi untuk banyak kegiatan yang ada di Museum dan salah satunya promosi yang terbatas ini. Maka dari itu dengan dana yang sangat minim ini membutuhkan usaha keras untuk berupaya menaikan kesadaran masyarakat agar mau berkunjung ke Museum ini.

\section{Lokasi yang tidak strategis yang sepi dan jauh dari keramaian}

Museum Balaputra Dewa terletak di Jalan Srijaya Lokasi sering kali menjadi faktor penting yang mempengaruhi berapa banyak nya pengunjung suatu objek wisata. Lokasi objek wisata yang dekat dengan pusat keramaian pasti akan lebih gampang menarik wisatawan untuk berkunjung ke objek wisata tersebut dibanding dengan lokasi yang objek wisatanya yang berada pada tempat Alang-Alang Lebar Sukarame kota palembang lokasi tersebut hanya dilalui oleh kendaraan pribadi karena letak bangunan Museum Balaputra Dewa menjorok kedalam dari bahu jalan raya sehingga tidak banyak pengunjung yang tahu disana hanya ada sekolah dan didepan Museum terdapat gardu-gardu PLN (Perusahaan Listrik Negara) PT.PLN (Persero).

\section{Tersedia Fasilitas Pendukung}

Selain pelayan yang akan di berikan Museum ternyata fasilitas pendukung menjadi nilai tambah dan sangat mempengaruhi tingkat suasana yang akan di ciptakan di dalam Museum. Fasilitas atau sarana pendukung tersebut antara lain tempat parkir, kantin Museum, perpustakaan, toko souvernir, area istirahat seperti taman-taman yang ada di dalam Museum, toilet 4 umum yang kurang terawat 3 toilet diruang pegawai 1 diruang kepala Museum yang sangat baik dan audio visual atau media seperti kaset program dan prasarana pendukung seperti Auditorium Museum.

\section{Budaya Organisasi}

Museum Balaputra Dewa di bawah naungan Dinas Kebudayaan dan Pariwisata provinsi yang mempunyai struktur organisasi yang sangat jelas antara yang satu dengan yang lain 
masing-masing bagian menjalankan tugasnya sesuai tugas pokok dan fungsi yang diharapkan. Akan tetapi pelaksaan itu belum efektif karena setiap hari pengunjung yang datang terbilang sedikit. Biasanya yang bertugas untuk mengguide melihat disana sepi maka lebih memilih untuk tetap berada di dalam ruangan. Akan tetapi jika dilihat dari struktur organisasi secara keseluruhan sudah berjalan baik karena masingmasing pegawai mempumyai tugas yang jelas dan terstruktur.

\section{Tidak adanya petunjuk arah masuk}

Pemasangan papan arah wajib di pasang kembali seperti semula agar wisatawan tidak tersesat atau perjalanan bisa lebih lama. Apabila ingin meningkatkan pengunjung Museum harus meningkatkan kembali tentang pelayanan dan memperbaiki sarana yang ada. Pencopotan plang rambu arah jalan masuk tersebut dahulu nya pernah ada akan tetapi semenjak adanya pembangunan Ligth Rail Transit (LRT) plang petunjuk arah jalan tersebut di copot atau di cabut oleh Satuan Pamong Praja (SatPol PP).

\section{Tiket Masuk Relatif Murah}

Tiket masuk Museum Negeri Sumatera Selatan Balaputra Dewa sangat terjangkau bagi semua kalangan masyarakat salah satu pemasukan untuk Museum Negeri Sumatera Selatan Balaputra Dewa berasal dari dana APBD dan pemasukan yang lain berasal dari penjualan tiket untuk masuk ke Museum. Harga tiket untuk masuk ke Museum Balaputra Dewa relatif sangat murah, yaitu tiket untuk dewasa perorangnya Rp.2000 -, dan anak-anak perorangnya Rp.1000-Harga tiket yang relatif murah tersebut sangat terjangkau oleh masyarakat secara umum tidak perlu mengeluarkan biaya yang banyak untuk menikmati berwisata keMuseum dan mendalami apa-apa yang ada di dalam Museum Balaputra Dewa.

\section{Dana}

Segala kegiatan yang dilakukan diMuseum berasal dari APBD akan tetapi Museum Tahun 2018 mendapatkan dana yang lebih rendah dibandingkan Tahun 2017 dan bila dibandingkan dengan Museum provinsi lain Museum Balaputra Dewa ketinggalan jauh lalu bagaimana kegiatan promosi terlaksana dengan baik.

\section{Museum miliki koleksi tentang sejarah kejayaan masa lampau di Sumatera Selatan}

Sumatera Selatan mempunyai sejarah panjang tentang keberadaanya. Provinsi yang sejak berabad lampau di kenal bumi Sriwijaya ini merupakan lokasi berdirinya dari kerajaan termansyur di nusantara yang bernama kerajaan Sriwijaya. Memasuki abad ke 15, berdiri kesultanan palembang yang bermasa yang berkuasa sampai kedatangan kolonialisme belanda ke bumi sriwijaya merupakan salah satu wilayah di nusantara yang banyak sekali penemuan di pemukiman tentang zaman megalith.

\section{Kualitas dan Kuantitas Cindramata}

Salah satu kekurangan yang harus segera di sikapi oleh pihak Museum adalah cinderamata yang dapat diberikan oleh Museum Negeri Sumatera Selatan Balaputra Dewa apabila ada suatu acara dan kegiatan. Alangka baiknya apabila cinderamata bisa dijual kepada pengunjung karena suatu kebahagiaan tersendiri bagi pengunjung pulang 
membawa oleh-oleh dari tempat yang dikunjungi. Cinderamata bisa dapat dijadikan salah satu media promosi bagi Museum.

Tabel 2. Cinderamata

\begin{tabular}{lll}
\hline Cinderamata & Tahun & Jumlah \\
\hline $\begin{array}{l}\text { Kerajinan } \\
\text { Lacker }\end{array}$ & 2014 & 45 \\
\hline $\begin{array}{l}\text { Kerajinan } \\
\text { Lacker }\end{array}$ & 2015 & 50 \\
\hline Pin & 2014 & 100 \\
\hline Mug/Cangkir & 2015 & 50 \\
\hline
\end{tabular}

Sumber: diolah oleh Penulis

\section{Berpotensi sebagai tempat untuk penelitian dan wisata edukatif}

Wisata edukatif Museum

Balaputra Dewa membantu para pelajar berkunjung untuk bisa belajar dengan cara melihat langsung hal itu membuat para pelajar lebih bisa mengerti dan membayangkan bagaimana sejarah kebudayaan kejayaan masa lampau di bandingkan hanya belajar di dalam kelas dan membaca terori dari buku-buku pelajaran di sekolah (hasil wawancara dengan kepala Museum Balaputra Dewa).

\section{PEMBAHASAN}

Hasil penelitian analisis lingkungan Eksternal dan Internal maka digunakam analisis SWOT dengan pendekatan matriks kualitatif yang akan menghasilkan 4 (empat) kemungkinan prioritas strategi alternative yaitu:

1. Strategi SO (Strenght and Opportunities), yaitu strategi yang mengoptimalkan kekuatan (Strength) untuk memanfaatkan peluang (Opportunities) yaitu: a. Pengembangan sarana pendukung lebih diefektifkan lagi.

b. Menyusun usaha bersama sebuah aturan di dalam musuem tentang pelayanan kepada pengunjung.

c. Membangun Museum yang nyaman dan perkembangan nya berkelanjutan maka Museum harus menjalin kerja sama dengan pihak terkait.

d. Meningkatkan

SDM berkemampuan tinggi di Museum

2. Strategi ST (Strength and Threats) yaitu strategi yang menggunakan kekuatan (strength) untuk mengatasi ancaman (threats) yaitu:

a. Usaha melestarikan dalam mengembangkan Museum

b. Menyediakan informasi berupa data Museum sebagai media promosi

c. Mengadakan kerja sama dengan stakeholder seperti Koran, tv

d. Mengembangkan inovasi wisata bersejarah dan budaya.

3. Strategi WO (Weaknesses and Opportunities) yaitu strategi yang meminimalkan kelemahan (Weaknesses) untuk memanfaatkan peluang (Opportunities) yaitu:

a. Melakukan promosi melalui media masa internet, televisi, maupun berupa sms kepada setiap wisatawan turun dari bandara.

b. Meningkatkan koordinasi dengan stakeholder seperti pihak swasta PT. Telkom dan Telkomsel, PT. Sharp dalam menjalankan program Museum.

c. Memotivasi masyarakat agar turun berperan aktif dalam menyediakan cinderamata agar 
menambah penghasilan.

d. Memperbaiki fasilitas yang ada seperti petunjuk arah dan kotak saran.

4. Strategi WT (Weaknesses and Threats) yaitu strategi yang meminimalkan kelemahan (Weaknesses) dan menghindari ancaman (Threats) yaitu:

a. Memberikan suatu arahan agar persepsi masyarakat sadar penting nya Museum.

b. Meningkatkan keamanan berupa cctv dan security.

c. Meningkatkan sosialisasi cinta Museum

d. Mengoptimalkan potensi destinasi Museum agar mampum bersaing dengan wisata lain.

\section{KESIMPULAN DAN SARAN}

\section{Kesimpulan}

Berdasarkan hasil penelitian dan pembahasan maka kesimpulan yang dapat ditarik adalah sebagai berikut:

1. Aspek Internal yaitu Kekuatan (Strenghts): Tiket masuk, Fasilitas pendukung, Tempat penelitian/wisata edukatif, Musuem memiliki koleksikoleksi kejayaan masa lampau, Budaya Organisasi. Kelemahan (Weaknesses): tidak ada petunjuk arah, lokasi tidak strategis, kuantitatif dan kualitatif barang cinderamata, dana. Aspek Eksternal Peluang (Opportunities): Kebijakan Pemerintah, Kemajuan IPTEK, Destinasi pariwisata menawarkan produk, Koordinasi dinas terkait, kenyamanaan. Ancaman (threats): Kondisi sosial budaya masyarakat yang menilai wisata Museum. Masuknya budaya asing, Persaingan tempat hiburan,Pencurian, Perusakan.

2. Hasil analisa aspek internal dan eksternal dengan menggunakan metode SWOT yaitu pendekatan matriks kualitatif maka strategi pengembangan Museum Negeri Sumatera Selatan "Balaputra Dewa" termasuk kepada matriks ketiga pada diagram SWOT. Alternatif strategi yang digunakan adalah strategi WO (Weaknesses and Opportunities). Museum Balaputra Dewa sendiri memiliki kemampuan yang masih bisa dikembangkan menjadi lebih baik lagi akan tetapi kemampuan itu belum optimal untuk itu Museum harus menciptakan strategi dengan menggunakan strategi yang meminimalkan kelemahan (Weaknesses) untuk memanfaatkan peluang (Opportunities). Sementara itu peluang harus dimanfaatkan untuk meminimalkan kelemahan yang dimiliki serta dipakai untuk mengurangi ancaman eksternal.

3. Penurunannya Anggaran Dana APBD yang menyebabkan Promosi terbatas karena Keuangan merupakan hal yang sangat vital bagi kelangsungan suatu organisasi, karena keuangan adalah hal mendasar yang tidak bisa dilepaskan dalam menjalankan organisasi dengan keuangan yang baik maka suatu organisasi akan berjalan dengan baik pula.

4. Sumber Daya Manusia amat sangat terbatas baik dalam jumlah maupun kualitas. Dari segi latar belakang pendidikan dan keahlian sebagian besar pegawai tidak memiliki latar 
belakang yang dibutuhkan oleh Museum. SDM manusia yang tersedia sebagian besar karena proses belajar yang telah menahun.

5. Kritik adalah upaya kita membangun diri untuk menjadi lebih baik dari sekarang. Kritik terhadap Museum dapat dijadikan senjata mengetuk pandangan masyarakat terhadap Museum. Karena Museum ada untuk masyarakat. Artinya masyarakat juga harus ada untuk Museum.

\section{Saran}

1. Menambah fasilitas penting seperti petunjuk arah, wahana dan kotak saran karena dari hal yang disepelehkan itu sangat berarti untuk perkembangan Museum.

2. Lebih memperbaiki pemeliharaan dan pengawasan security Cctv maupun pegawai agar tidak terjadinya perusakan dan pencurian benda-benda koleksi yang ada di Museum.

3. Memberikan suatu arahan agar persepsi masyarakat sadar pentingnya Museum sehingga minat masyarakat untuk mengenal sejarah kejayaan masa lampau lebih baik lagi dan tidak sama sekali tepengaruh budaya asing yang masuk.

4. Memotivasi masyarakat agar turun berperan aktif dalam perkembangan Museum Balaputra Dewa dan Alangka baiknya cinderamata yang ada itu dijual sehingga bisa mendapatkan penghasilan tambahan dan membuat pengunjung bangga membawa pulang cinderamata Museum.
5. Pengajuan usulan kegiatan kepada Pemerintah Provinsi Sumatera selatan melalui Dinas Kebudayaan dan Pariwisata lebih diperbanyak agar anggaran APBD bisa sebanding dengan kegiatan yang dilaksanakan.

\section{DAFTAR PUSTAKA}

[1] Peraturan pemerintah Republik Indonesia Nomor 66 tahun 2015 tentang Museum

[2] S.Saragih, Meriati,dkk. (2016). Buku panduan Museum negeri Balaputera Dewa Sumatera selatan. Palembang.

[3] Yenni Salim. (2002). Kamus Bahasa Indonesia Kontemporer. Modern English. Jakarta: Press.Jakarta.

[4] Siagian,Sondang P. (2005). Manajemen Strategi.Jakarta:Bumi Aksara.

[5] Wahyudi, Agustinus Sri. (1996). Manajemen Strategik, Pengantar Proses Berfikir Strategik. Jakarta: Binarupa Aksara

[6] Rangkuti,Freddy. (2006). Analisis SWOT,Teknik Membedah Kasus Bisnis.Cetakkan Kedua Belas. Jakarta: PT.Gramedia Pustaka Utama. 